\title{
A STUDY ON THE EFFECTIVENESS OF RADIO JINGLES AMONG YOUTH
}

\section{LINCY JOSEPH}

Assistant Professor, Department of Communication and Journalism, Pazhassiraja College, Pulpally, Kerala, India

ABSTRACT
There isn't any doubt that music can elicit various responses from people. Music can calm us, excite us, emotionally
move us, sadden us, soothe us and might even coordinate us at work. We can without doubt state that music is pretty an
essential component in how we perceive things in our day to day lives. Jingles are produced for promoting product or
service or brand name. Jingles are one of the vital elements in all mass radio stations. Each radio station selects the
proper music most suitable for the advertising and brand carefully to get positive reception from listeners. The primary
focus of this research is to determine if the jingles in numerous radio stations affect the listening behaviour of youth.
This research has used survey method to study the objectives. And it found that jingles help to attract youth to
programmes.
KEYWORDS: Radio, jingles, listeners, survey method, brand name

Received: Jan 26, 2021; Accepted: Feb 16, 2021; Published: Mar 12, 2021; Paper Id.: IJCMSAPR20211

\subsection{INTRODUCTION}

Humans are capable of recalling music they've heard for a lifetime, in addition to the feelings it triggered. We are completely able to memorize thousands, if not more, musical pieces in our life, including music elements like lyrics, melody, tempo, rhythm or even pitch. Music is produced in diverse ways and with unique purpose. Jingles are produced for selling services or products or brand name. Jingles are one of the crucial factors in all of radio. The radio stations choose the right music which can best suit the brand advertising carefully to get positive reception from the listeners.

\subsection{Radio Jingles}

A jingle is a radio marketing slogan set to a memorable melody. Jingles are written explicitly for a product. They may be unique works designed to explain about a product or service, or to enable easy recall for product information. As long as the slogan are catchy and difficult to ignore there may be nearly no limit to what advertisers can use in a jingle. It may be a slogan, a contact number, a radio station's call letters, a business's brand or maybe the advantages of a product.

The jingle contains one or more hooks and lyrics that explicitly promote the product being advertised, typically through the usage of one or more marketing slogans. Ad buyer makes use of jingles in radio and TV commercials; they also can be utilized in non-marketing context to set up or maintain a brand. Jingles are a form of sound branding.

The jingle had no definitive status: its infiltration of the radio was more of an evolutionary method than an unexpected innovation. Product ads with a musical tilt may be traced back to 1923, across the same time commercial radio started out within the United States. If one entity has the simplest claim to the 
primary jingle it's General Mills, who aired the world's first making a singing commercial. The seminal radio bite, entitled "Have You Tried Wheaties?" become first sung over the air on Christmas Eve of 1926 in Minneapolis St. Paul radio market.

The art of the jingle reached its peak during the economic boon of the 1950s. The jingle was used in marketing of branded merchandise like breakfast cereals, candy, snacks, soda pop, tobacco, and beer. As radio is concerned with the voice, jingles had crucial roles in every radio program. All most all radio commercials and stations are primarily based on jingles for their identification.

\subsection{REVIEW OF LITERATURE}

Fraser. C and Bradford. J (2013) focused that with the practice of background music like jingles, tones, sonic emblems improved the image of the brand in the minds of buyer. This paper concluded that auditory scene analysis (ASA) includes 3 structural music characteristics categories i.e. harmonic elements, textual elements and Tempo. These work together and jointly influence processing and recall of brand.

G and Craton. L(2011) studied the consumer's attitude towards the advertising music like jingles. Jingles and other musical elements in the ads lead to high degree of involvement for the product and hence the liking for the product. Jingles possess a theme-based message - enhancing trait such music are generally attention getting, distinctive, and are likely to affect customer's perception for the product. These musical elements in ads leads to recall of ads and these jingles and slogans result more effectively affecting customers than other verbal elements imbibed in the ad with the jingles. It studies the cognitive and affective components affecting attitude towards and thereby the buying behaviour of the customer.

A study on the effects of jingles \& music in marketing (2014) published Mrs. Simran R Kalyani says that song is all round us and is a constant in our lives. Although the music that we listen changes over time. What is "in" nowadays might also additionally be "out" tomorrow. With the astronomical quantity of music that surrounds us in our ordinary lives isn't any surprise that corporations use it as a mean to market their products and services to us. Combining them both is sheer genius. Music can accomplish many things whilst integrated with advertisements. In marketing it's used to entertain, as a mnemonic tool to trigger memory, and to target a particular demographic. When music is utilized in marketing for entertainment it makes the commercial more attractive to its target audience. The study indicates that ladies have a propensity of being receptive to jingles related to merchandise or manufacturers designed for ladies and the identical is true for men for jingles promoting "men" merchandise or manufacturers. The preference for certain music does not show an effect at the ability to identify jingles or slogans.

The study titled Impact of Songs and Jingles Used in Advertising on Brand and Product Awareness (2012) by Bc. Iveta Karailievova focuses on the intensifying utilization of TV and radio of communication with consumers through music and jingles. A good jingle catches the customer's interest and makes him (or her) think twice about a product; a terrible jingle may make a corporation well-known for the incorrect reasons, or dissuade people from a certain brand.

\subsection{STATEMENT OF THE PROBLEM}

Radio stands as an entertainment medium in competing with other media. Audio or sound is a vital a part of radio encompassing voice and music. Music has ended up a critical a part of the radio. With the intensifying usage of radio as a 
means of communication with people, accordingly music and jingles cannot be neglected. Jingle is the most common musical method for assisting memorability. A good jingle catches the listener's interest and makes him (or her) think twice about a specific radio station and the listener end up a regular listener. In this situation the problem has been taken up for study to explore whether the radio jingles are influenced among youth to follow the radio programme in competing with other media in concern with various radio stations of the state.

\subsection{OBJECTIVES OF THE STUDY}

The objectives of the study are:

- To verify that whether radio jingles are really being to influence youth to follow programs.

- To find out whether jingles attract the listener to follow the program.

- To find out the element that makes the listener gravitate towards radio.

- To verify that jingles really make an emotional connection with radio.

\subsection{METHODOLOGY}

A research is a careful and details study of a selected problem or concern using a scientific approach. The motive of this study is to discover whether or not radio jingles influence young people to follow the program. The study has been done with the help of quantitative research approach.

\subsubsection{Quantitative Research Method}

Quantitative Research is used to quantify the problem via generating numerical data transformed into usable statistics. It is used to quantify attitudes, opinions, behaviours, and different described variables - and generalize consequences from a bigger pattern populace. Quantitative Research makes use of measurable statistics to formulate information and discover styles in studies.

\subsubsection{Survey Method}

Survey approach is a quantitative approach wherein a researcher poses a few sets of pre organized inquiries to a whole institution, or some individuals. Through survey research, the researcher describes the characteristics or features of people. Here the survey is used to understand and explain about how the radio jingle gains popularity among youth.

\subsubsection{Sampling Procedure}

Purposive Sampling is used for the study, where the researcher selects a sample based on information about the population and the study itself. The study participants are selected based on the study's purpose.

\subsubsection{DATA COLLECTION TOOL}

\subsubsection{1 : Questionnaire}

A questionnaire is an information gathering instrument. It can be structured or unstructured. It is less expensive manner to acquire information from a potentially huge number of respondents. 


\subsection{WHY RADIO MANGO, RADIO MIRCHI AND RED FM?}

According to the listenership Radio Mango, Radio Mirchi, and Red Fm are very high in comparing with other radio stations. Red Fm broadcasts to 38 cities in India. Radio Mango is Kerala's No.1 FM network as per IRS 2012, and also as per a syndicated study conducted by IMRB in 2016 March. All Radio Mirchi stations are being broadcasted 24 hours. So the researcher has selected these radio stations for the study.

\subsection{OPERATIONAL DEFINITION}

\subsubsection{Jingle}

Radio Jingles may be used collectively to explain all factors of radio station branding or identification. A jingle is a radio or TV marketing slogan set to a memorable melody.

\subsubsection{Youth}

Youth is the time of existence while one is young, and regularly refers to the time among childhood and adulthood. It is likewise described as the appearance, freshness and who is young.

\subsubsection{Radio}

Radio is the wireless transmission of signals via free space by electromagnetic radiation of a frequency. Radio is a background medium where it can be listened while we do other works.

\subsection{DISCUSSIONS}

Survey was conducted among youth to collect data pertaining to the objective of study. 360 samples were selected among youth to find out the effectiveness of radio jingles. 213 male participants, 144 female participants and 3 transgenders were surveyed through questionnaire. These 360 participants listened to radio regularly, especially FM radio. Saraswati (1988) labelled the youngsters belonging to the age group 15 - 34 years into 3 subgroups such as — sub junior youngsters (15-19 years), - junior youngsters (20 - 24 years) and — senior youngsters (25 - 34 years) (In Devendiran, 2010). In the study $40 \%$ of sample fall into the junior youth category and 30\% of sample belongs to sub junior youth and $30 \%$ belongs to senior youth.

\subsubsection{Element of attraction}

There are different elements included in a radio programme like voice, music, sound effects and script which catch the attention of the listener. The table discuss about the element that attract the listener to the radio. Whether music or speech based, radio relies on the human voice to connect to its audience. It is the voices of presenters and RJ's that we respond to on a radio. They are the personification of a radio, providing a personality with which we identify and connect. The fashion of music each station plays is an important aspect of the station's identity. In any event, the music played on radio stations is governed by a policy developed to appeal to the station's target audience. A radio show script is a norm in the stations throughout the nation. While it could seem that things are flowing naturally, you may assume that a radio show script is being used. Most radio shows are live, and to avoid disaster, will make use of a radio show script for the visitors and personalities alike. 
Table 1.8.1: Element of Attraction

\begin{tabular}{|l|c|c|}
\hline Particulars & No of Respondents & Percentage \\
\hline Voice & 36 & 10 \\
\hline Music & 226 & 63 \\
\hline Sound effect & 45 & 12.5 \\
\hline Script & 52 & 14.5 \\
\hline Total & $\mathbf{3 6 0}$ & $\mathbf{1 0 0}$ \\
\hline
\end{tabular}

The table shows that music is the element that attracts listeners to the radio program mostly. It says that $63 \%$ of the respondents are attracted by music. Remaining $14.5 \%$ of respondents are attracted to the radio by the script and $12.5 \%$ are attracted to the radio by the sound effect. Only $10 \%$ of samples are attracted to a radio programme by its voice or sound.

\subsubsection{Jingle attracts the listener}

The question looks ahead to know the cause of listening the radio whether it is jingle or not.

Table 1.8.2: Jingle Attracts the listener

\begin{tabular}{|c|c|c|}
\hline Particulars & No of Respondents & Percentage \\
\hline Yes & 260 & 72 \\
\hline No & 100 & 28 \\
\hline Total & $\mathbf{3 6 0}$ & $\mathbf{1 0 0}$ \\
\hline
\end{tabular}

It says that $72 \%$ of listeners are listening radio because the radio jingles are highly attractive. On the other side $28 \%$ of listeners is listening radio are not influenced by the radio jingles. Therefore, we can conclude jingles are influencing youth to follow a radio program.

\subsubsection{Reasons for using Radio Jingles}

Radio stations play jingles regularly during an advert break, because the listener is much more likely to remain tuned in; given that those catchy tunes aren't as irritating as a few commercials, they're performed in between songs to preserve continuity. Jingles clutter and monotony, making for smoother transitions whilst getting back to a non-stop music sweep too. This part of the study list out the motives for the usage of radio jingle.

Table 1.8.3: Reasons for Using Radio Jingles

\begin{tabular}{|l|c|c|}
\hline \multicolumn{1}{|c|}{ Particulars } & No of Respondents & Percentage \\
\hline Branding & 84 & 23 \\
\hline Remembering & 108 & 30 \\
\hline Repetition & 153 & 43 \\
\hline Other & 15 & 4 \\
\hline Total & $\mathbf{3 6 0}$ & $\mathbf{1 0 0}$ \\
\hline
\end{tabular}

It is understood $43 \%$ of listeners agree with repetition and $30 \%$ people agree with remembering value of jingle. But branding constitutes only $23 \% .4 \%$ people did not agree with any of the above. The study reveals that real cause of using radio jingles is repetition. 


\subsubsection{Element of Radio Jingle}

Radio jingle is made up of music, phrases, brand name, words, etc. The table provides an answer about a relevant element of the radio jingle that influencing the listener to pay more attention.

Table 1.8.4: Element of Radio Jingle

\begin{tabular}{|l|c|c|}
\hline Particulars & No of Respondents & Percentage \\
\hline Music & 225 & 63 \\
\hline Brand name & 30 & 8 \\
\hline Words & 105 & 29 \\
\hline Other & 0 & 0 \\
\hline Total & $\mathbf{3 6 0}$ & $\mathbf{1 0 0}$ \\
\hline
\end{tabular}

The table shows the most important component in the radio jingle. The respondents show that $63 \%$ people considered music as a best component or element in a radio jingle . 29\% people are saying words are the influential component. The least attentive component in radio jingle is the brand name.

\subsubsection{Listenership of Radio Station Based on Radio Jingle}

It is important to study whether listener want to listen to the radio station with their most favourite radio jingle.

Table 1.8.5 Listenership of Radio Station Based on Radio Jingle

\begin{tabular}{|r|c|c|}
\hline Particulars & No of Respondents & Percentage \\
\hline Yes & 253 & 70 \\
\hline No & 107 & 30 \\
\hline Total & $\mathbf{3 6 0}$ & $\mathbf{1 0 0}$ \\
\hline
\end{tabular}

It says that the majority of the listeners listen to the radio station with their favourite radio jingle. $70 \%$ of listeners listen to a radio based on radio jingle and only $30 \%$ of respondents do not listen to a radio station based on radio jingle. So jingle plays an important role in attracting listeners to the radio programme.

\subsubsection{Recognition of Radio Station by the Jingles}

It is important to study whether the listeners of a radio station can recognize station by its station's jingle. And $92 \%$ of respondents could recognize their radio station by hearing station's jingles. Only eight percentage of respondents couldn't recognize the station by its jingle. It means jingles are an effective medium in listening to the radio station. 
1.8.7: Effectiveness of Radio Jingles

\begin{tabular}{|c|c|c|c|c|c|c|}
\hline SI No & Statements &  &  & : & 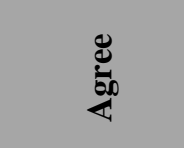 & 离 \\
\hline 1. & Music is memorable & $12(3 \%)$ & $19(5 \%)$ & 0 & $201(56 \%)$ & $128(36 \%)$ \\
\hline 2. & $\begin{array}{l}\text { Jingles are always } \\
\text { remembrance music }\end{array}$ & $23(6 \%)$ & $27(7.5 \%)$ & $19(5.5 \%)$ & $187(52 \%)$ & $104(29 \%)$ \\
\hline 3. & $\begin{array}{l}\text { Radio jingles exhibit } \\
\text { brand features }\end{array}$ & $\begin{array}{c}11(3.5 \\
\%)\end{array}$ & $44(12 \%)$ & $03(1 \%)$ & $216(60 \%)$ & $86(24 \%)$ \\
\hline 4. & $\begin{array}{l}\text { While listening to the } \\
\text { jingles; the audience has } \\
\text { an emotional relationship } \\
\text { with radio station. }\end{array}$ & $33(9 \%)$ & $17(5 \%)$ & $8(2 \%)$ & $201(56 \%)$ & $101(28 \%)$ \\
\hline 5. & $\begin{array}{l}\text { Radio jingles increase } \\
\text { the popularity of radio } \\
\text { stations among young } \\
\text { adults. }\end{array}$ & $15(4 \%)$ & $18(5 \%)$ & $12(3 \%)$ & $208(58 \%)$ & $107(30 \%)$ \\
\hline 6. & $\begin{array}{l}\text { Radio jingles attract } \\
\text { youth to the programmes }\end{array}$ & $\begin{array}{c}20(5.5 \\
\%)\end{array}$ & $45(12.5 \%)$ & 0 & $197(54.5 \%)$ & $98(27.5 \%)$ \\
\hline
\end{tabular}

From the above table, majority of the respondents agree that jingles are always a type of music which can be remembered. And jingles exhibit brand features. Thus it helps to identify the brand while they listen to jingles where ever they are. Majority of the respondents agree that they have an emotional relationship with radio station as they enjoy jingles. Radio jingles increase the popularity of radio stations among young adults. Music can invoke both emotion and nostalgia among the listeners. And jingles are really an effective medium in making the youth to listen.

\subsection{FINDINGS AND RESULTS}

The study reveals that jingles are an effective medium which makes the youth to enjoy their radio station. Radio jingles increase the popularity of radio stations among youth. Jingles cause an emotional connection with radio stations. Jingles do not provide a brand consistency about the station. Jingles are a memorable melody in radio stations.

Study reveals that radio jingles are really influencing youth to follow programs. The researcher found the best element that makes the listener towards radio is music. People listens jingles occasionally during travel. The researcher found that the reason for remembering radio jingle is the easiness of memorizing jingles. The study shows that jingles do attract more than programs. The listeners are able to identify the radio station while hearing the jingle. The survey shows that radio jingles exhibit the brand features of radio.

\subsection{CONCLUSIONS}

Radio jingles are an effective medium in communicating with the people. People are capable recalling music for a lifetime, in addition to the emotions it triggered. Listeners memorize thousands of lyrics, melody, tempo, rhythm or perhaps pitch. At present there are different types of jingles used by various radio stations in attracting the listeners. Some of the jingles are highly attractive to listeners. This paper is a study on the effectiveness of radio jingles among youth. The study has done among the youth. Here 120 youth have been taken as samples and using quantitative method surveyed the youth. The study reveals that jingles are really an effective element in tuning in to the radio stations and also one of the reasons to listen the radio by the youth. Jingles make an emotional connection with radio. 


\subsection{LIMITATION}

The study was limited with youth so, to find out the listeners of radio was a difficult task. Some of the respondents were reluctant to provide adequate information. There is a decreasing tendency in listening radio and so the selection of sample was a difficult task. The study has been done through online so face to face interaction with the samples were not done

\subsection{RECOMMENDATION}

Jingles are the essential part of a radio station. Jingles have the power to catch the audience towards the radio programs. Since the study has been done among youth so the samples were very low. In future the topic can include all walks of people for the study. Secondly the jingles which were selected were within the state. In future the study can include different stations' jingles. So the study can be done with a larger sample base.

\section{REFERENCES}

1. Fraser. C and Bradford. J, (2013) Music to your brain: Background music to changes are processed first, reducing ad message recall. Psychology \& Marketing Volume 30, Issue 1, pages 62-75, January 2013, DOI: 10. 1002/mar. 20580

2. Bhawna Ahuja \& Gurjit Kaur, "Throughput Analysis of Cooperative Spectrum Sensing for Cognitive Radio Network", International Journal of Computer Networking, Wireless and Mobile Communications (IJCNWMC), Vol. 5, Issue 6, pp, 1-8

3. Craton. L and Lantos. G, (2011) Attitude towards the advertising music: an overlooked potential pitfall in commercials. Journal of Consumer Marketing, Vol. 28 Iss:6, pp. 396 - 411, DOI: 10. 1108/07363761111165912

4. Archana Bhatt \& S. K. Kashyap, "Prioritizing Needs for Community Radio Broadcast for Livelihood Improvement: A Study of Pantnagar Janvani Community Radio Service of Uttarakhand", International Journal of Applied and Natural Sciences (IJANS), Vol. 5, Issue 5, pp; 63-72

5. KALIYANI, S. R. (2014). A study on the effects of jingles \& music in advertising. An online interdisciplinary, multidisciplinary \& multi-cultural journal, 2-5.

6. Bhavna Pathak, "The Community Radio Movement in India: Challenges and Opportunities", International Journal of Communication and Media Studies (IJCMS), Vol. 9, Issue 2, pp, 1-8

7. Karailievová, B. I. (2012). Impact of Songs and Jingles Used in Advertising. 4-6.

8. Jaya Lakshmi, J. Swetha \& G. N. Swamy, "Enhanced Multi-Transmitter Based Channel Selection Matching System for Cognitive Radio Ad Hoc Network", IMPACT: International Journal of Computational Sciencesand Information Technology ( IMPACT: IJCSIT ); Vol. 1, Issue 1, pp, 1-12

9. Le, J. N. (2010). An overview of jingles and popular music and the emotional impact of music in advertising. Music in advertising .

10. Akinjiyan, R. D. (2015). Radio listening habits among university students and their attitude towards programmes. Radio listening habits among university students and their Research on Humanities and Social Sciences, 1-5.

11. Caraline, J. (2011). Music's Impact On Implicit And Explicit Attitudes Singing Your Way Into The Consumer's Mind. 5 to 6.

12. Craig, S. (2011). A Brief History of the American Radio Jingle ., (pp. 7 - 10).

13. Friday-Otun, J. O. (2015). Language Of Competition In The Station-Promoting Jingles of Radio: A Study of Broadcasting Stations in Kwara State Nigeria. Joseph Omoniyi

14. Friday-Otun in Journal of the Linguistic Association of Nigeria Volume 18, 2-5. 
15. Gorn, G. J. (1982). A Classical Conditioning Approach. The Effects of Music in Advertising on Choice Behaviour , 15 -18.

16. Hoeberichts, M. a. (2012). The Effect of Music in Television Commercials on Consumer Attitudes . Music and Advertising , 1015.

17. Johansen, G. (2010). A study of radio as an advertising media. Theater of the mind, 5-10.

18. Johnson, C. (2011). Singing your way into the Consumer's Mind: Music's Impact onImplicit and Explicit Attitudes. MUSIC"S IMPACT ON IMPLICIT AND EXPLICIT ATTITUDES , 3-6.

19. KALIYANI, S. R. (2014). A study on the effects of jingles \& music in advertising. an online interdisciplinary, multidisciplinary \& multi-cultural journal, 2-5.

20. Karailievová, B. I. (2012). Impact of Songs and Jingles Used in Advertising. 4-6.

21. Michelle Heaton, K. P. (2006). The Effects of Music Congruency and Lyrics on Advertisement Recall. UW-L Journal of Undergraduate Research IX, 7- 15.

22. Nwosu, O. (2015). The Ballot and the Bard: Oral Poetry, Radio Jingles, and Electioneering Campaigns in Selected States of South Eastern Nigeria. IKENGA International Journal of Institute of African Studies UNN Vol. 17, No.1 , 1 -7.

23. Obukoadata, \& Ogheneruke Presly and Dodo, W. A. (2009). sociological bases of radio jingles and audience perception. sociological bases , 22-24.

24. S.Fischler, A. (2009). Quantitative research method. Nova south eastern university, 1-5. Thinkstock, \& White, T. (2004). pioneers of radio. A short history of radio, $1-6$.

25. Blog Radio king. (2017, may 26). Retrieved july 2018, from popular types of radio programms: https://www.radioking.com/blog/popular-types-of-radio-programs/

26. Engineers Garage. (2017). Retrieved JULY 2018, from Difference between AM and FM: https://www.engineersgarage.com/contribution/difference-between-am-and-fm-modulation

27. Georgial. (2016). raadioring. Retrieved june monday, 2018, from www.raadioring.ee: http://www.raadioring.ee/types-radiostations/jingles India. (n.d.). Retrieved july 12, 2018, from jingles.co.in: https://www.jingles.co.in/those-were the-day.

28. Stephen. (2010). classes, stephens, Radio\%20history\%20page.htm. Retrieved from www.nyu.edu: https://www.nyu.edu/classes/stephens/Radio\%20history\%20page.htm

29. W.Careswell, J. (2010). Qualitative and quanditative and mixed methos approaches. Research Design, Thired Edition. 
